\title{
Religi pada Masa Kerajaan Sunda Kawali (Telaah Atas Prasasti Pendek di Situs Astana Gede, Kawali)
}

\section{Nanang Saptono}

Keywords: Astana Gede, Kingdom of Sunda, inscription, religion, megalithic

\section{How to Cite:}

Saptono, N. . Religi pada Masa Kerajaan Sunda Kawali (Telaah Atas Prasasti Pendek di Situs
Astana
Gede,
Kawali).
Berkala
Arkeologi,
14(2),
68-72.

https://doi.org/10.30883/jba.v14i2.703

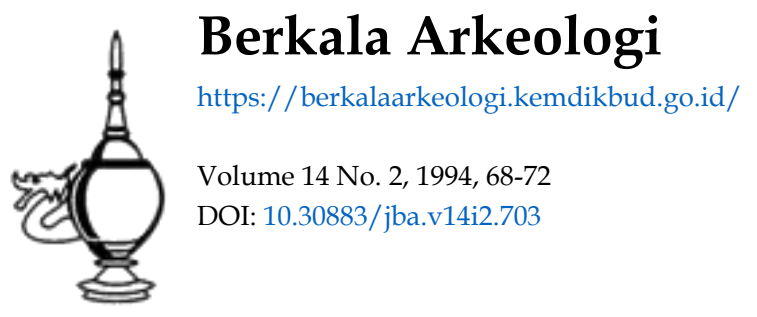

\section{(c) (i) (9)}

This work is licensed under a Creative Commons Attribution-NonCommercial-ShareAlike 4.0 International License. 


\title{
RELIGI PADA MASA KERAJAAN SUNDA KAWALI (Telaah Atas Prasasti Pendek di Situs Astana Gede, Kawali)
}

\author{
Nanang Saptono \\ (Balai Arkeologi Bandung)
}

\begin{abstract}
Situs Astana Gede terletak di Dusun Indrayasa, Desa Kawali, Kec Kawali, Kab. Ciamis, Jawa Barat dikenal sebagai salah satu bekas ıbukota Kerajaan Sunda. Di situs ini terdapat beberapa data arkeologıs antara lain berupa prasastı berhuruf dan berbahasa Sunda Kuna. Luas situs sekıtar 5 hektar berada di kaki Gunung Sawal bagian tımur Seluruh situs berupa hutan lındung yang dijadikan objek wisata budaya. Di sebelah selatan situs berjarak sekitar 150 meter mengalir Sungai Cibulan. Di sebelah barat situs sekitar 300 meter terdapat mata air yang oleh penduduk dinamakan mata air Cikawali. Kompleks Astana Gede merupakan kompleks arkeologıs yang bercirikan budaya megalitik, namun terdapat juga unsur budaya klasik dan Islam.

Secara umum Situs Astana Gede terbagi dalam beberapa teras. Pada teras pertama (ter atas) terdapat dua buah punden yang dihubung. kan dengan tatanan batu, makam kuna dari masa islam Pada teras kedua terdapat beberapa tınggaian arkeologis antara lain pelinggih, batu datar berınskrıpsı (Prasastı Kawali 1), lempengan batu berınskrips! (Prasasti Kawali II), batu tapak berınskrıpsı (Prasasti Kawali III), dan sebaran batu berdirı (menhir) Pada teras ketiga (teras terbawah) terdapat beberapa batu berdiri. Dua buah batu berdiri di antaranya berinskripsi Sanghyang lingga hiyang (Prasasti Kawali IV) dan Sanghyang lingga bingba (Prasastı Kawal! V). Kesemua tinggalan tersebut keletakannya kurang beraturan (Tim Penelitian Ciamis,1993:35-41). Sampal saat ını. Situs Astana Gede dianggap sebagai salah satu bekas ibukota Kerajaan Sunda. Dalam makalah ini akan dicoba diulas masalah religi yang melatarbelakangi pendukung budaya situs tersebut. Kajian religi didasarkan atas prasastı pendek pada dua buah batu berdiri (Prasasti Kawali IV dan V) yang terdapat di teras ketiga
\end{abstract}

\section{Kerajaan Sunda Secara Singkat}

Sejarah kuna Jawa Barat pada abad IV-VII $M$ telah mencatat adanya Kerajaan Tarumanagara. Runtuhnya Tarumanagara kemudian digantikan oleh Kerajaan Sunda. Berita Portugis dari Tome Pires menyebutkan adanya kerajaan dı Jawa Barat bernama regño de çumda telah mengadakan hubungan dagang dengan Portugis (Cortesao, 1944:412-416). Berita Cina dari dinasti Ming menyebut-nyebut kerajaan Sunla (Groeneveldt, 1960 44) Prasastı Kebon Kopı (854 Ç / 932 M),
Bogor menyebut adanya ba(r) pulihkan hafl sunda. Naskah kuna Carita Parahyangan menyebut Sunda sebagai nama kawasan (Sumadio, 1990 356). Sebagaimana kerajaan yang lain, ibukota Kerajaan Sunda mengalamı beberapa kali perpındahan, dimulai darı Galuh dan berakhır di Pakwan Pajajaran.

\section{Kerajaan Sunda di Galuh}

Di dalam Carita Parahyangan disebut nama Sañjaya. Tokoh ini juga terdapat pada prasasti Canggal (732 M). Di dalam prasastı tersebut, Sañjaya dikatakan telah menggantikan raja sebelumnya yang bernama Sanna. Antara Sañjaya dengan Sanna masıh ada hubungan darah Carita Parahyangan menghubungkan tokoh Sañjaya dengan pusat Kerajaan Galuh, karena d situ dikatakan bahwa Sëna, berkuasa di Galuh Sañjaya juga disebut sebagaı menantu Raja Sunda yang bernama Tarusbawa. Karena perkawınan tersebut, Sañjaya dapat berkuasa atas Kerajaan Sunda. Sejak itu Kerajaan Sunda berpusat di Galuh (sebelah barat Citarum) (Sumadio,1990 357-358). Bersamaan dengan kenaikan tahta Sañjaya, di Jawa Barat juga terdapat kerajaan lain yang diperintah oleh Sang Söwökarma, yang berkedudukan di Saunggalah

\section{Kerajaan Sunda di Prahajyan Sunda}

Prasasti lebıh muda yang menyebut Kerajaan Sunda yaitu prasasti Sanghyang Tapak berangka tahun 952 C / 1030 M. Dalam prasast menyebutkan tokoh bernama Maharaja Srı Jayabhupati Jayamanahen Wisnumurtti Samarawijaya Sakalabhuwanamandaleswaranindita Haro Gowardhana Wikramottunggadewa. Daerah kekuasaannya disebut Prahajyan Sunda. Srı Jayabhupati, dalam naskah Carita Parahyangan dapat disejajarkan dengan Sang Rakeyan Darmasiksa. Apabila hal ini benar, maka dapat diduga pada masa ini pusat kerajaan terletak di Pakwan Pajajaran (Sumadio, 1990:360-364)

\section{Kerajaan Sunda di Kawali}

Entah pada masa pemerintahan sıapa, ibukota kerajaan pindah ke Kawali. Secara jelas dalam prasasti Kawali menyebutkan pada masa pemerintahan Prabu Raja Wastu ibukota telah berada di Kawali. Keterangan tentang ibukota kerajaan di Kawali terdapat juga dalam naskan Sanghyang Siksakanda ng Karesian (1518 M) 
Nama Prabu Raja Wastu juga terdapat pada prasastı lain yaitu pada prasasti Batutulis (Purbacaraka 1921) dan prasasti Kebantenan (Pleyte 1911; Bucharı 1985:104). Pada kedua prasasti itu disebut Rahyang Niskala Wastu Kañcana.

Prasastı Kebantenan menyebutkan raja-raja pengganti Niskala Wastu Kañcana. Sepeninggal Wastu Kariıcana digantikan oleh Rahyang Ningrat Kañcana, kemudian digantikan Susuhunan ayöna di Pakwan Pajajaran. Prasasti Batutulis menyebutkan bahwa maharaja penguasa Pakwan Pajajaran adalah cucu Niskala Wastu Kañcana, putra Rahyang Dewaniskala. Prasasti ini memuat juga tempat moksa (surup) Niskala Wastu Kañcana yaitu di Nusalarang, dan Rahyang Dewaniskala di Gunungtiga (Ayatrohaedi, 1986:26)

Carita Parahyangan juga menyebutkan bahwa Prabu Niskala Wastu Kañcana surup di nusalarang ring giri wanakusumah sedangkan penggantınya, yaitu Rahyang Dewanıskala, nu surup di gunungtilu. Dalam Carita Parahyangan, nama Rahyang Dewaniskala tidak disebutkan, hanya disebut Tohaan di Galuh. Dengan demikıan melaluı Carita Parahyangan dapat diketahui bahwa sampai pada masa pemerintahannya, pusat kerajaan Sunda masih terletak di Galuh, tepatnya di sekitar Kawali sekarang (Sumadio 1990 366)

Darı ketıga raja Sunda Kawali, yang paling banyak mendapat perhatian adalah Prabu Nis. kala Wastu Kañcana. Pemberitaan dimulai dari peristiwa Bubat Secara syah, ketika itu ia sudah naik tahta tapi karena masih kecıl, maka pemerıntahan Kerajaan Sunda dipegang oleh Hyang Bunisora. Setelah Hyang Bunisora menınggal dunıa pada tahun 1371, ia memegang pemerintahan. Menurut Carita Parahyangan, Wastu Kañcana memerintah selama 104 tahun (1371-1475 M). Pada masa pemerintahannya berhasıl membawa suasana yang sangat positif,

nya mana sang rama e(na)k mangan, sang résı enak ngaresisana, ngawakan na purbatisti. purbajati, sang dis(r)i enak masini ngawakan na manusasana, ngaduman alas pari-alas, ku beet hamo diukih. ku gejde hamo diukih. nya mana sang tarahan enak lalayaran ngawakan manuràjasasana. sanghyang apa(r). teja, bayu, akasa, sangbu enak-enak ngalu(ng)guh di sanghyang jagat-palaka. ngawakan sanghyang rajasasana. angadég di sanghyang linggawési, brata siya puja tanpa lum. sang wiku e(na)k ngadewasasana ngawakan sanghyang watangagöng, enak ngadég manuraja.sunya .. "artinya ... itulah sebabnya para tetua di dusun nikmat makan, para pendeta dengan tenteram menjalankan peraturan kependetaan, mengamalkan purbatisti purbajatı (adat dan tradisi leluhur). Para dukun dengan tenteram membuat perjanjlan-perjanjian dengan mempergunakan aturan yang berkenaan dengan kehidupan, membagi-bagi hutan dan $\mathrm{k}_{\text {j- }}$ tarannya, baik oleh si kecil maupun sı besar tak akan terjadı kerewelan, bahkan para bajak laut pun merasa aman berlayar sesual dengan peraturan raja. Air, cahaya, angın, langit, dan bumi pun merasa senang berada dalam genggaman pelindung dunia. Berpegang kepada pedoman raja, berdiri pada Sanghyang Linggawesi, berpua. sa, memuja (dewa) tanpa batas Para pendeta dengan tenang menjalankan ajaran dewa, mengamalkan Sanghyang Watangagöng. Mereka melepaskan kedudukan berdasarkan keyakinan (Sumadio,1990: 367-368, Ayatrohaedi, 1986:28 29) Kebesaran Wastu Kañcana selaın dibeberkan di dalam Carita Parahyangan, temyata juga terdapat di dalam carita pantun, yang hıdup di masyarakat Jawa Barat sebagal cerita tutur. Dalam cerita tutur tersebut, Wastu Kañcana dianggap sebagai tokoh Prabu Siliwangi (Ayatrohaed 1986: 34)

\section{Kerajaan Sunda di Pakwan Pajajaran}

Di depan sudah dijelaskan bahwa sepeninggal Wastu Kañcana, pemerıntahan di KeraJaan Sunda digantikan oleh Tohaan di Galuh atau Ningrat Kañcana. Pada masa pemerıntahannya ternyata tidak begitu banyak berita yang terdapat pada prasasti maupun Carita Parahyangan Ningrat Kañcana kemudian digantikan oleh anaknya yang bernama Sang Ratu Jayadewata Pada prasasti Kebantenan, tokoh in disebut Susuhunan ayöna di Pakwan Pajajaran. Pada prasast Batutulis, tokoh ins disebut Prabu Guru Dewataprana, Sri Baduga Maharaja Ratu Haji di Pakwan Pajajaran Sri Sang Ratu Dewata. Pada prasast tersebut, tokoh ini juga diberitakan ya nu nyusukna pakwan (Yang membangun parit di Pakwan). Dengan demikian dapat disimpulkan bahwa pada masa pemerintahannya, pusat kerajaan sudah berpindah dari Kawali ke Pakwan Pajajaran (Sumadio, 1990:368-369) Menurut berita Portugis dari Tomé Pires, pada masa ini sudah mulai ada penetrası darı masyarakat Islam (Cortesáo, 1944:1973). Sejak itulah Kerajaan Sunda mulai memasuki masa kemundurannya.

\section{Keagamaan Kerajaan Sunda Dalam Data Etno- ejarah}

Mengenar keagamaan zaman Kerajaan Sunda di antaranya dapat dilihat darı berbagaı sumber etnosejarah antara lain dari naskah kuna atau prasasti. Naskah Carita Paranyangan banyak memberıkan gambaran tentang keadaan keagamaan pada zaman itu. Di dalam naskah ını menyebut bahwa Sañjaya yang beragama Hındu memberi nasehat kepada anaknya yang bernama 
Rahyang Tamperan atau Rakeyan Panaraban, agar tidak mengikuti agama yang dipeluknya. Dari sini seakan-akan dapat diketahui bahwa setelah Sañjaya, agama Hindu tidak lagi berkembang. Tetapi dalam bagian yang lain, Carita Parahyangan menceritakan tentang Sanghyang Darmasiksa yang dikatakan sebagai titisan Batara Wisnu.

Darı sumber lainnya yaitu Prasasti Sanghyang Tapak, memperlihatkan kuatnya pengaruh agama Hindu Nampaknya kuatnya pengaruh Hindu in merupakan kelanjutan dari zaman Kerajaan Tárumanágara pada awal abad ke-5 M. Pengaruh Hindu juga tampak kuat pada naskah kuna Sawakadarma. Naskah ini ditulis pada tahun 1357 Ç/ 1435 M. Dalam naskah ini terdapat nama-nama dewa dari agama Hindu antara lain Brahma, Wisnu, Maheswara, Rudra, Sadasiwa, Yama, Baruna, Kuwera, Indra, Besrawáka.

Dalam naskah Sanghyang Siksakanda ng Karêsian pengaruh agama Hındu juga masıh terlihat. Namun demikian juga tampak adanya pengaruh agama Buddha. Dalam naskah itu menyebutkan ".. in na lakukönön. talatah sang sadu jati hongkara namo sewaya, sembah ing hulun di sanghyang pañcatatagata; pañca ngaran ing lima, lata ma ngaran ing sabda, gata ma ngaran ing raga ya eta ma pahayuon sareanana. (.. inilah yang harus dilakukan (yaitu) amanat Sang Barkhati (terpercaya) yang sejati. Selamatlah (hendaknya) dengan nama Siwa, menyembahlah hamba kepada Sanghyang Pañcatatagata (Buddha), pañca berartı lıma, tata itu artinya sabda, gata itu artınya raga, ya Itulah untuk kebaikan semuanya ... . Pada bagıan laın terdapat keterangan ".. mangkubum bakti dı ratu, ratu bakti di dewata dewata bakti di hyang .. ( mangkubumı berbaktı kepada ratu. ratu berbaktı kepada dewata, dewata berbakti kepada hyang .. ).

Darı berbagal keterangan tersebut menunjukkan bahwa pada awalnya, keagamaan yang melatarı Kerajaan Sunda adalah Hindu. Dalam perkembangannya agama Hindu bercampur dengan agama Buddha, dan pada akhirnya unsur kepercayaan asli muncul. Kemunculan kepercayaan asll dari para leluhur terlihat dari keterangan dalam naskah Sanghyang Siksakanda ng Karêsian yang menurunkan derajat Dewata berada di bawah Hyang (Sumadio, 1990:390-392; Ayatrohaedi, 1982:337-338). Perkembangan keagamaan tersebut selain terlinat pada data etnosejarah juga terlihat pada beberapa tinggalan arkeologis

Tinjauan Sıngkat Tentang Situs Astana Gede, Kawali

Pada beberapa kajıan, Situs Astana Gede di Desa Kawali disebut-sebut sebagal bekas sa- lah satu Ibukota Kerajaan Sunda Beberapa carita pantun menerangkan bahwa bentuk kraton Kerajaan Sunda terdiri darı lima buah bangunan yang disebut pañca pérsada. Bangunan induk dinamakan Suriadipati. Bangunan kelengkapan yang lain dinamakan Bıma. Punta. Narayana, dan Madura (Sumadio, 1990:384). Dari kelima unsur tersebut, belum semuanya diketahui tentang fungsi masing-masing bangunan. Pada beberapa prasasti darı masa Kerajaan Sunda, kraton sebagai pusat ibukota kerajaan juga dikelilingi parit Susunan kraton yang demikian ini selaras dengan doktrin ajaran Brahma dan Budhis pada konsep kosmologis. Dengan demikian kraton tidak hanya berfungsi sebagai pusat pemerintahan, tetapi juga pusat magis kerajaan (Geldern 1982: 4-6)

Situs Astana Gede, bila disimpulkan sebagai bekas kraton tampaknya terlalu dini. Berdasarkan bukti-bukti yang ada, mungkin lebih bijaksana bila dikatakan sebagal bagian dari ibukota Kerajaan Sunda. Data arkeologıs yang menarik minat banyak ahli untuk menelitinya adalah beberapa prasasti dan beberapa bangunan yang bercirikan budaya megaiitık

Pembacaan terhadap prasasti pernah dilakukan oleh Friederich (1855). Kesimpulan dari hasil pembacaannya Ialah adanya pertapaan ke punyaan Parebu Raja Wastu yang berkuasa di Kraton Surawisesa, yang telah membuat parit sekeliling kota, serta mendirikan desa-desa Pada prasasti tersebut juga termuat harapan semoga masyarakat mengerjakan kebaikan untuk memperoleh kebahagiaan dikemudian hari (Friederich 1855: 170). Prasasti tersebut pada keadaan sekarang dinamakan prasasti Kawali I. Selain Friederich, prasasti tersebut juga telah ditelaah Holle (1867:464-467) dan Pleyte (1911:167). Dari kese muanya pada dasarnya tidak terdapat perbedaan pendapat mengenal is! prasastı

Prasasti laın yang menyebut harapan untuk orang-orang yang mendiami daerah Kawaii supaya memperoleh kemenangan dalam peperangan Prasasti ini disebut prasastı Kawali II. Prasast, Kawali III lebih singkat. hanya terdiri dari dua kata dan terdapat goresan membentuk petak-petak berjumlah 45 buah, serta tapak tangan dan kakı. Prasasti Kawail IV berupa sebuah batu berdırı yang terdapat tulisan. Tulısan yang ada juga sangat singkat Menurut Friederich tulisan tersebut merupakan nama dewa yaitu Sanghyang innga hyang. Dewa ini merupakan saiah satu dewa yang dipuja di situ pada waktu itu (Friederich. 1855:181). Prasasti Kawalı V, juga berupa sebuah batu berdiri yang terdapat tulisan Tulisan yang ada berbunyı Sanghyang lingga bingba. Menurut Holle, mungkın merupakan nama dewa atau raja yang diperdewakan. Holle mengasumsikan bahwa Sanghyang lingga bingba adalah 
nama seorang raja Galuh yang menjadi pertapa (Holle, 1867 468). Dari beberapa keterangan yang terdapat di dalam prasasti tersebut, terdapat gambaran bahwa situs Astana Gede merupakan suatu situs untuk pemujaan

Gambaran tentang sarana pemujaan, tampak pada tinggalan bangunan yang bercirikan budaya megalitik. Bentuk-bentuk bangunan berupa punden berundak yang pada salah satu terasnya, dilengkapi semacam pelinggih. Pada semua teras ditemukan batu berdiri (Tim Penelitian Ciamis 1993 36). Batu-batu berdiri tersebut ada yang berfungsı sebagai batas, ada juga yang berdiri sendıri sebagai objek pemujaan.

\section{Religi Pada Masa Kerajaan Sunda Kawali \\ Di depan sudah disinggung bahwa berda-} sarkan data etnosejarah, pada masa Kerajaan Sunda telah berkembang agama Hindu, Buddha, serta kepercayaan asli. Pada masa-masa awal, agama Hindu terlihat lebih dominan. Hindu yang berkembang pada masa itu bercirikan pada pemujaan terhadap Wisnu. Adanya pemujaan kepada Wisnu terlihat pada masa raja Sanghyang Darmasiksa. Di dalam prasasti Sanghyang Ta pak, nama raja disebutkan Maharaja Sri Jayabhupati Jayamanahen Wisnumurtti Samarawijaya Sakalabhuwanamandaleswaranindita Haro Go wardhana Wikramottunggadewa. Nama tersebut mengandung unsur Wisnumurtti yang dapat dihubungkan dengan Dewa Wisnu. Adanya unsur Wikramottunggadewa, mengingatkan pada gelar yang dipakai Airlangga yang juga penganut Waisnawa Pada sumber yang lain, dapat diketahui bahwa agama Budha juga pernah berkembang. Naskah Sanghyang Siksakandha ng Karêsian menyebut adanya pemujaan kepada Pañcatatagata

Untuk mengetahui relıgı pada masa Kawali dapat dijumpai pada prasasti yang terdapat di situs Astana Gede. Menurut pengamatan Friederich terhadap prasasti Kawali I, didapatkan atribut yang menyerupai cakra dan trisula. Cakra dianggap merupakan roda cakra dari kepercayaan Buddha sedangkan trisula merupakan atribut dari agama Hindu (Çıwa). Dengan demikian pada masa Kawali telah berkembang dua agama yang menyatu yaitu Ciwa-Budha (Freiderich 1855:158).

Dua buah prasasti pendek, yaitu Prasasti Kawali IV dan V menyebutkan Sanghyang Lingga Hyang dan Sanghyang Lingga Bingba. Dari sebutan tersebut dapat diduga bahwa relıgi yang melatarbelakangı adalah agama Hindu khususnya Siwa. Hal tersebut karena lingga merupakan lambang Siwa Pemujaan kepada lingga (Ciwa) juga diberitakan dalam Carita Parahyangan. Diceritakan bahwa pada masa pemerintahan Wastu Kañcana semua peri kehidupan berdiri pada Sanghyang Lınggawèsı (Sumadio, 1990:368).
Jika dilihat dari tinggalan arkeologıs yang terdapat di situs Astana Gede, menunjukkan adanya unsur tradisi megalitik. Sanghyang lingga hyang dan Sanghyang lingga bingba pada prasasti Kawali IV dan $V$ adalah sebuah batu berdin. Dengan adanya batu berdiri tersebut, dapat dihubungkan dengan kepercayaan asli. Religi dari kepercayaan asli merupakan tradisi megalitik yang memberikan identitas kehidupan yang bersumber pada kepercayaan terhadap arwah nenek moyang. Tradisi semacam ıni berkembang darı masa prasejarah hingga pada masa sekarang (Sukendar, 1993:8). Di situs Astana Gede, batu berdlri tidak hanya digunakan sebagai media prasast tetapi juga banyak terdapat pada teras yang lain. Ternyata tidak semua batu berdiri ada hubungannya dengan pemujaan. Batu berdiri ada juga yang berfungsi sebagai batas dari objek tertentu Batu berdiri yang ada hubungannya dengan pemujaan disebut menhir, sedangkan yang tidak ada hubungannya dengan pemujaan disebut batu berdiri (Sukendar, 1985:100). Demikian halnya yang terdapat di situs Astana Gede. Menurut Holle (1867:486) batu berdiri yang dijadikan media prasasti Kawali IV dan V, ada hubungannya dengan unsur pemujaan. Kalimat yang tergores pada batu tersebut merupakan nama dewa atau raja yang diperdewakan. Bentuk fisık lingga yang disebutkan prasati Kawali IV dan $V$ pada dasar. nya bukan lingga sebagaimana dalam agama Hindu tetapi menhir sebagaimana yang telah dikenal pada tradisi megalitik. Dengan demikian adanya pemujaan kepada Sang hyang iıngga hyang dan Sang hyang lingga bingba mengandung unsur pemujaan kepada arwah leluhur yang diwujudkan dengan bangunan menhir. Dari sını dapat disimpulkan bahwa religı pada masa Sunda Kawali merupakan campuran darı agama Hındu, baik Waisnawa maupun Çiwa, Buddha, serta kepercayaan asli dari masa prasejarah

\section{KEPUSTAKAAN}

Ayatrohaedi,1982. Masyarakat Sunda Sedelum islam. PIA II Jakarta Pusat Penelitian Arkeologı Nasıonal, hım. 333 - 346

Ayatrohaedi, 1986, Niskalawastukancana (1348-1475)

Raja Sunda Terbesar? dalam PIA IV Buku Ila, Jakarta:Pusat Penelitian Arkeolog Nasional, him 25-36

Bambang Sumadio (ed.).1990, Jamar Kuna Sejarah Nasional Indonesia II, Jakarta Balai Pustaka 
Bucharı, 1985, Prasasti Koleksi Museum Nasional Jilid I, Jakarta: Museum Nasional.

Cortesaio, Armando, 1944, The Suma Oriental of Tomé Pires, London: The Hakluyt Society

Friederich, R. Th., 1853. Verklaring van de BatoeToelis van Buitenzorg dalam T.B.G. I him $441 \cdot 468$

Geldern, Robert Heine., 1982, Konsepsi Tentang Negara \& Kedudukan Raja di Asia tenggara, terj.Deliar Noer, Jakarta:CV. Rajawali

Harls Sukendar, 1985, Peranan Menhir Dalam Masyarakat Prasejarah di Indonesia dalam PIA III, Jakarta:Pusat Penelitian Arkeologi Nasional

Haris Sukendar, 1993, Dınamika Dan Kepribadian Bangsa Yang Tericermin Dari Tradisi Megalitik di indonesia pada Pidato Pengukuhan Jabatan Ahli Peneliti Utama, Jakarta 13 November.

Holle, KF, 1867, Viuigtig berigt omtrent eenige lontar-handschrieften. afkomstig uit de
Soendalanden door Raden Saleh aan het Bataviaasche Genootschap van Kunsten en Wetenschappen ten geschenken gegeven met toepassing op de inscriptien van Kawali, T.B.G. XVI, him. $456-470$.

Krom, N.J., 1915.Rapporten Van De Oudheidkundigen Dienst in Nederlandsch-Indie (ROD) 1914, Uitgegeven door het Bataviasch Genoots chap van Kunsten en Wetenschappen

Pleyte,C.M. 1911. Het jaartal op den Batce Toeirs nabij Buitenzorg, T.B.G. LIII. hlm 155 - 220

Purbacaraka, R. Ng., 1921. De Batoe Toelis nabij Buitenzorg, T.B.G. LIII. hlm. 380 - 218

Raffles, Th.S.,1817. History of Java Vol \| London

Tim Penelitian Ciamıs,1993. Survei Situs-situs Prasejarah: Tinjauan Aspek Keruangan Di Kecamatan Cijulang dan Sekitarnya, Bandung: Balai Arkeologi Bandung 